\title{
An Expert System Framework for Design of Bending Die
}

\author{
Deepak Panghal ${ }^{1}$, S. Kumar ${ }^{2, *}$ \\ ${ }^{1}$ NIFT, New Delhi, India \\ ${ }^{2}$ Dept. of Mechanical Engineering, S. V. National Institute of Technology, Surat, India
}

\begin{abstract}
This paper presents an expert system framework for design of bending die. Considerations for development of expert system are discussed at some length. The proposed framework divides the task of development of expert system into different modules for major activities of bending die design. It gives stress on automation of four major activities of die design viz. manufacturability assessment, process planning, design/selection of die components and modeling of die components and die assembly. A procedure of development of expert system modules is also described at length. Production rules for each module are recommended to be coded in the AutoLISP language and designed to be loaded into the prompt area of AutoCAD or through user interface created using Visual Basic. Each module of the proposed framework is user interactive. The proposed system framework is flexible enough to accommodate new acquired knowledge. As the proposed system is implementable on a PC having AutoCAD software, therefore its low cost of implementation makes it affordable even by small scale sheet metal industries.
\end{abstract}

Keywords Expert System, Bending Die, AutoCAD, Sheet Metal Industries

\section{Introduction}

Sheet metal forming is one of the oldest manufacturing processes known to mankind and bending can probably be considered its most basic variant. Design of bending die is an important activity in sheet metal industries. Bending die design process involves various activities such as manufacturability assessment of bending parts, process planning, selection/design of die components and modeling of die components and die assembly. Traditional process of bending die design is tedious, complex, time consuming and being done by highly experienced die designers in industries[1, 2]. In recent years various computer aided systems have been developed to provide assistance in design of sheet metal parts and bending die. But human expertise is still needed to arrive at the final design and these softwares are unable to integrate various phases of die design[3, 4]. Also the cost of these softwares is too high and hence can't be affordable by small scale industries.

Many researchers have worked on development of expert system for process planning and design of bending dies. Researchers have used different techniques and tools, like rule based expert system (RBS), artificial neural network (ANN), case based reasoning (CBR), object oriented programming, and fuzzy logic etc. Lin and Peing[5]

* Corresponding author:

skbudhwar@med.svnit.ac.in (S. Kumar)

Published online at http://journal.sapub.org/ajis

Copyright (C) 2012 Scientific \& Academic Publishing. All Rights Reserved developed a prototype expert system of sheet-metal bending design with preliminary learning capabilities. Lin and Chang[6] developed an expert system using machine learning from neural networks for the selection of sheet metal bending tool. Ong et al.[7] described the application of fuzzy set theory for normalization and modeling of the set-up and bend sequencing process for sheet metal bending. Spring back in the air vee bending process was investigated by Inamdar et al.[8]. Kim et al.[9] proposed an automated design system for process planning and die design by using fuzzy set theory for an electric product with intricate piercing and bending operations. A method for solving the problem of bend sequencing in sheet metal manufacturing was presented by Rico et al.[10]. In order to reduce the calculation time to identify valid sequences, a method based on the part division in basic shapes (channels and spirals) was proposed. Duflou et al.[11] presented a tool selection methodology to be integrated in the automatic bend sequencing system. Pathak et al.[12] predicted the responses of sheet metal bending process using ANN. Sousa et al.[13] proposed an optimization method for the design of $\mathrm{V}$ and $\mathrm{U}$ bending sheet metal processes. They coupled the numerical simulation of sheet metal forming processes with an evolutionary genetic algorithm searching for optimal design parameters of the process. A prediction model of spring-back in wipe-bending process was developed by Kazan et al.[14] using ANN approach. Kontolatis and Vosniakos[15] applied sheet metal bending processes in a multitude of mechanical parts. Their work involves optimizing the sequence of designated bends taking into account the total processing and handling time, 
avoiding collisions of the sheet metal with tools and machine and respecting the dimensional accuracy constraints of the part. They replaced expert knowledge by stochastic search using a classic genetic algorithm. Baseri et al.[16] proposed a new fuzzy learning back-propagation (FLBP) algorithm to predict the spring-back using the data generated based on experimental observations. The performance of the model in training and testing is compared with those of the constant learning rate back-propagation (CLBP) and the variable learning rate back-propagation (VLBP) algorithms. Then the best model with the minimum mean absolute error (MAE) is selected to predict the spring-back. They concluded that the proposed FLBP algorithm has best performance in prediction of the spring-back with respect to the other algorithms. From the review of published literature in the area of bending die, following conclusions can be drawn -

(i) Most of the system developed for bending die requires skilled and experienced die designers' assistance to take appropriate decisions during various stages of process planning and design of die.

(ii) Most of the bending die design automation prototypes still have the disadvantages of the conventional architecture of expert systems and incapable of managing heterogeneous knowledge sources effectively.

(iii) Many researchers have explored the finite element method (FEM) to optimize the various design parameters of bending die. However, long computation time and expertise required to understand the results make these systems impractical for planning and design stages of deep drawing process.

Nowadays most of the sheet metal industries are facing acute shortage of skilled die designers. Further, the mobility of experienced die designers in stamping industries has caused much inconvenience to the sheet metal industries all over the world. Also the knowledge gained by die design experts after long years of experience is often not available to others even within the same company. It creates a vacuum whenever expert retires or leaves the company. Therefore, there is need to develop an expert system to assist process planners and die designers for design of bending die. The present work proposes an expert system framework for design of bending die. The proposed framework recommends the development of modules for various major activities of design of a bending die. It can be implemented on a PC having AutoCAD software, therefore its low cost of implementation makes it affordable even for small scale industries of developing countries.

\section{Consideration for Development of Expert System for Bending Die Design}

The basic considerations for development of expert system for bending die design involve the following -

(i) Identifying the major activities of bending die design with clear-cut objectives and deciding whether such tasks are practicable to build the expert system, (ii) Studying each activity critically for economic feasibility and manufacturability point of view,

(iii) Structuring traditional bending die design process and identifying various modules using expert system modular framework involving flow-charts, logic planning of functional components in form of modules,

(iv) Developing of functional objectives for each module,

(v) Selecting suitable hardware depending upon memory requirement, processing speed and needed configuration and selecting a suitable computer language to deal die design functional objectives for each module,

(vi) Analyze critically various factors responsible for decision-making in each module of expert system framework and accessing domain specific data, facts, and thumb of rules in form of recommendations of acquired knowledge for each module,

(vii) Framing of production rules for acquired recommendations for each module,

(viii) Verifying and testing the acquired domain knowledge for each module from the team of bending die design experts,

(ix) Identifying suitable knowledge representation technique for programming of acquired knowledge for each module through a suitable identified language,

(x) Validating and evaluating the knowledge-base system for implementation.

Keeping in view the above considerations, an expert system framework and the procedure for constructing modules for bending die design can be developed.

\section{Proposed Expert System Framework for Bending Die Design}

The proposed expert system framework for bending die design is depicted in Figure 1. The proposed framework recommends dividing the whole process of bending die design in to some major activities including manufacturability assessment of bending parts, process planning, design /selection of die components and modeling of bending die. For each major activity, various expert system modules are required to be developed. The modular program coded in AutoLISP is loaded in the prompt area of AutoCAD or through user interface created using Visual Basic. The user interacts with the structural modules through user interface using input part data. Expert system module developed for manufacturability assessment of bending parts checks the design features of the sheet metal parts from manufacturability point of view. Such checks are useful to reduce manufacturing defects and section weakness of the component. The knowledge base of this module is capable to check and give advice for modification if the design features such as bend angles, direction of bends, bend sequence etc. are not in accordance with the rules of good practice. On checking the part design from manufacturability point of view, process planning for bending operations is required to be done. Expert system modules for process planning must 
be capable to determine various major process parameters of bending such as blank size, bending force, bending sequence and spring back calculation. Separate modules are required to be developed for determination of each process parameter. Once the process planning is completed, the next important activity is design/selection of die components. The types of die components and their optimal sizes are selected using modules of pressure pad, stoppers, die block, punch (es), plate elements (stripper plate, punch plate, cushion plate etc.), strippers, die sets, fastening and locating elements of bending die. The outputs of all expert system modules of bending die are stored in different data files. The data stored in these files can be utilized for modeling of die components, die accessories, and die assembly using AutoCAD facilitates and AutoLISP routines.

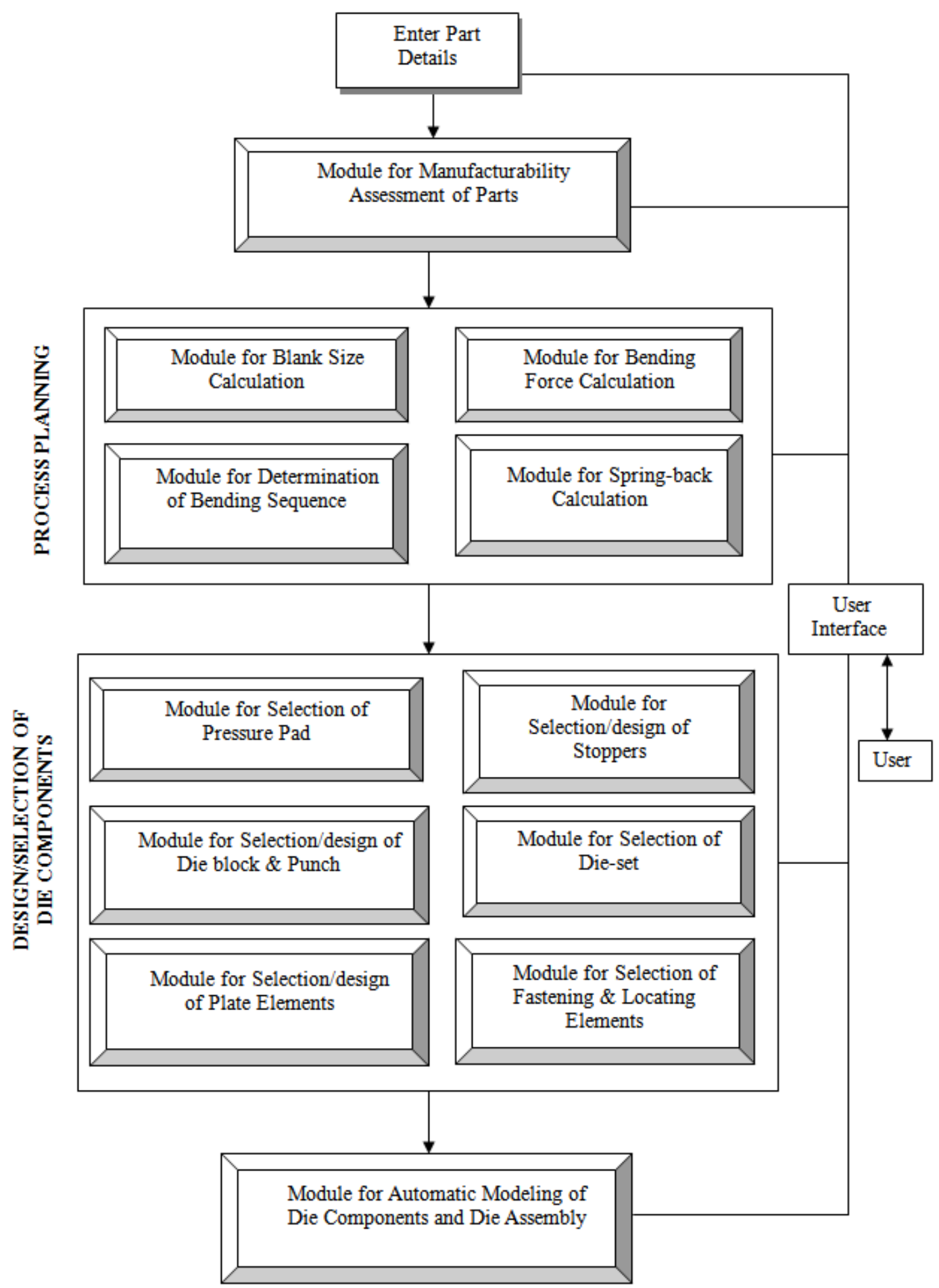

Figure 1. Proposed Expert System Framework for Design of Bending Die 


\section{Procedure for Development of Expert System Modules of the Proposed Framework}

The procedure for development of expert system modules for die design is schematically shown in Fig. 2. A brief description of each step is given as under[17]-

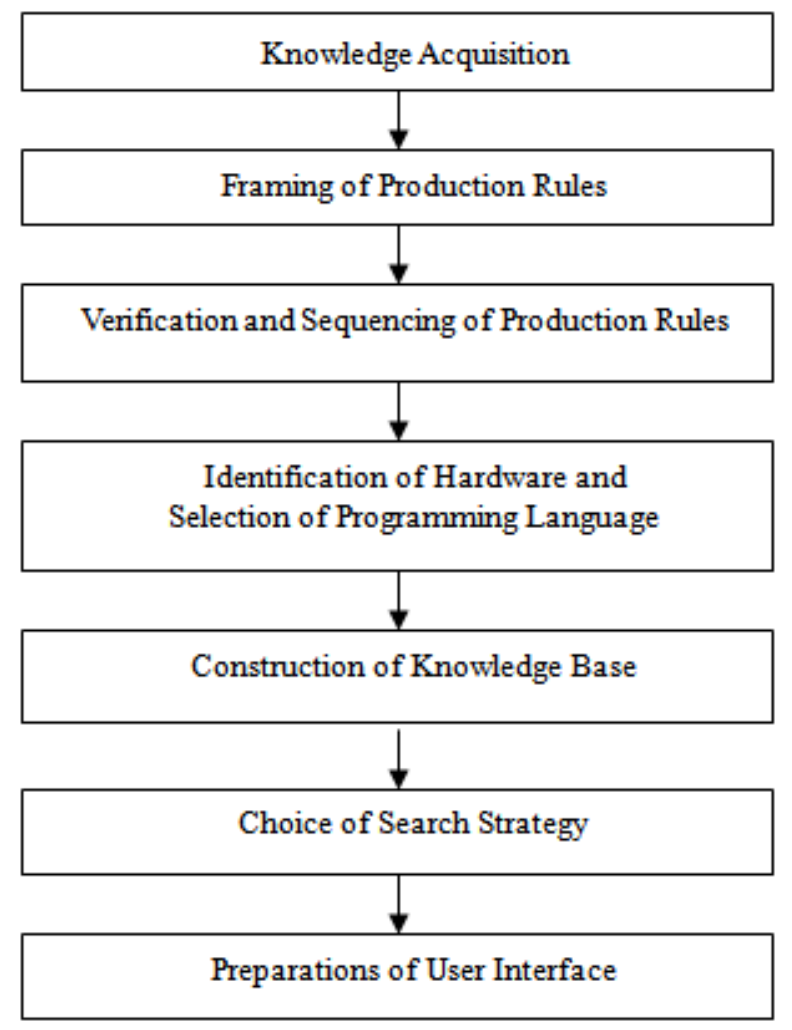

Figure 2. Procedure for Development of Expert System Modules of Proposed Framework

\subsection{Knowledge Acquisition}

Knowledge acquisition is first step in the development of an expert system module. It is most difficult and time consuming laborious task. The domain knowledge for design of bending die is required to be collected through on-line and off line consultation with die design experts, tool engineers of different industries, and referring published die design handbooks, research papers, catalogs and manuals of different design and manufacturing industries. The process of knowledge acquisition from die design experts involves presenting a few typical problems to the expert(s) and letting the expert(s) talk through the solution. During the verbal analysis, the expert(s) would be questioned to explain why a particular decision was reached.

\subsection{Framing of Production Rules}

The most common method of knowledge representation is rule-based. The syntax of a production rule is -

IF $<$ condition $>$

Then $<$ action $>$

The condition of a production rule, sometimes-called LHS (left-hand side) contains one or more conditions, while the action portion, sometimes called RHS (right-hand side) contains one or more actions.

\subsection{Verification and Sequencing of Production Rules}

The knowledge available for design of bending die is mostly collected from the experienced die designers. Usually these die designers use thumb rules, which they developed during long years of practice and experience in the area of die design. These rules may differ from industry to industry. So it is mandatory to come up on a common solution, which could be accepted by most of die designers working in various industries. Therefore the production rules framed for each module of proposed framework must be crosschecked from die design experts by presenting them IF-condition of the production rule of IF-THEN variety. The framed rules can be presented either in an unstructured (arbitrary) or a structured manner. But structured presentation of knowledge in form of production rules is simpler to refer, consume less time and if query is fired it take less time to get the result.

\subsection{Identification of Hardware and Selection of Programming Language}

Suitable hardware elements depending upon memory requirement, processing speed and needed configuration should be selected. Today, most of the KBS modules are being developed on a PC/AT because it involves low cost. Programming languages such as LISP and PROLOG have won wide acceptance for building expert systems. But the user of these languages encounters difficulties when handling design problems involving graphical information. For this reason, AutoCAD and AutoLISP have found greater acceptance for the development of expert system for die design.

\subsection{Construction of Knowledge Base}

Knowledge base is a part of an expert system that contains domain knowledge, which may be expressed in the form of production rules of IF-THEN variety. The inference mechanism allows manipulating the stored knowledge for solving problems. The rules and the knowledge base are linked together by an inference mechanism. The user input information provides guidance to the inference engine as to what 'IF-Then' rules to fire and what process of information is needed from the knowledge base.

\subsection{Choice of Search Strategy}

Inference mechanisms are control strategies or search techniques, which search through the knowledge base to arrive at decisions. The two popular methods of searching are backward chaining and forward chaining. Backward chaining is a goal-driven process, whereas forward chaining is data driven. Forward chaining is a good technique when all on most paths from any one of much initial or intermediate 
state converges at once or a few goal states. Backward chaining is an efficient technique to use when any of many goal states converging on one or a few initial states.

\subsection{Preparation of User Interface}

The expert system modules should be interactive in nature. The purpose of user interface in the development of each module is twofold - to enables the user to input the essential sheet metal component data; and to displays the optimal decision choices for the user's benefit. The former is accomplished by flashing AutoCAD prompts to the user at appropriate stages during a consultation to feed data items. Messages or items of advice are likewise flashed into the computer screen whenever relevant production rules are fired.

\section{Conclusions}

In the present work, an expert system framework for design of bending die has been proposed. The major activities of traditional design of bending die have been identified in form of expert system modules. The basic elements for constructing expert system modules for bending die design have been considered and analyzed critically in the present work. The procedure for the development of expert system modules is also discussed at some length. This methodology is being pursued for the development of various modules of the proposed framework. The proposed framework and methodology for building expert system for bending die design are capable of automating the die design process. The system supports the modifications in the knowledge base of each module depending upon the newly acquired knowledge and addition of new modules for updating the system capabilities. Using proposed framework, the process of expert system development for bending die design will be easier to implement. The framework can be implemented on a PC, has low cost and is user-friendly.

The proposed framework acts as a guideline for automation of design process of bending die using expert system approach. Authors are engaged in the development of various modules of this framework. Development of all modules of the proposed framework with rich knowledge base will not only automate the design of bending die but also provide a great assistance to the die designers of sheet metal industries.

\section{REFRENCES}

[1] H.M.A.Hussein and S.Kumar, "A computerized retrieval system for sheet metal parts", Asian Int. J. Science and Technology in Production and Manufacturing, Vol.1(2), pp.31-40, 2008.

[2] R. G. Narayanan, "Expert system applications in sheet metal forming", Expert systems book (editor- Petrica Vizureanu),
INTECH, Croatia, pp.92-116, 2010.

[3] S.Q. Xie, Y.L. Tu, J.Q. Liu, and Z.D.Zhou, "Integrated concurrent approach for compound sheet metal cutting and punching”, Int. J. Prod. Res., pp. 1095-1112, 2001.

[4] V. Naranje and S. Kumar, "A knowledge based system for selection of components of deep drawing die", American Journal of Intelligent Systems, Vol.2 (2), pp.1-11, 2012.

[5] Zone-Ching Lin, Gow-Jeng Peing, "An investigation of an expert system for sheet-metal bending design", Journal of Materials Processing Technology, Vol. 43, pp. 165-176, 1994.

[6] Z.C. Lin, and D.Y. Chang, "The Selection System for Sheet Bending Tooling", Int. J Advanced Manufacturing Technology, Vol 11(2), pp. 127-135, 1996.

[7] S.K. Ong, L.J.D. Vin, A.Y.C. Nee, and H.J.J. Kals, "Fuzzy set theory applied to bend sequencing for sheet metal bending", Journal of Materials Processing Technology, Vol. 69, pp. 29-36, 1997.

[8] M. Inamdar, P.P.Date, K. Narasimhan, S.K. Maiti, and U.P. Singh, "Development of an Artificial Neural Network to Predict Springback in Air Vee Bending", Int J Advanced Manufacturing Technology, Vol. 16, pp. 376-381, 2000.

[9] C. Kim, Y.S. Park, J. H. Kim, and J.C. Choi, "A study on the development of computer-aided process planning system for electric product with bending and piercing operations", Journal of Materials Processing Technology, Vol. 130-131 pp. 626-631, 2002.

[10] J.C. Rico, J.M. Gonzalez, S. Mateos, E. Cuesta, and G. Valino, "Automatic determination of bending sequences for sheet metal parts with parallel bends", Int. J. Production Research, Vol. 41(14), pp. 3272-3299, 2003.

[11] J. R. Duflou, T.H.M. Nguyen, J.-P. Kruth, and D.Cattrysse, "Automated Tool Selection for Computer-Aided Process Planning in Sheet Metal Bending", CIRP Annals Manufacturing Technology, Vol. 54(1), pp. 451-454, 2005.

[12] K.K.Pathak, S. Panthi, and N. Ramakrishnan, "Application of Neural Network in Sheet Metal Bending Process", Defence Science Journal, Vol. 55 (2), pp.125-131, 2005.

[13] L.C. Sousa, C.F. Castro, and C.A.C. Antonio, "Optimal design of $\mathrm{V}$ and $\mathrm{U}$ bending processes using genetic algorithms", Journal of Materials Processing Technology, Vol. 172, pp. 35-41, 2006.

[14] R. Kazan, M. Firat, and A.E.Tiryaki, "Prediction of springback in wipe-bending process of sheet metal using neural network", Materials and Design, Vol. 30, pp. 418-423, 2009.

[15] N. Kontolatis, and G.C. Vosniakos, "Optimisation of press-brake bending operations in 3D space", J Intelligent Manufacturing, Vol. 23(3), pp. 457-469, 2012.

[16] H. Baseri, M.B. Jooybari, and B. Rahmani, "Modeling of spring-back in $\mathrm{V}$-die bending process by using fuzzy learning back-propagation algorithm", Expert Systems with Applications, Vol. 38, pp. 8894-8900, 2011.

[17] S. Kumar, and R. Singh, "An automated design system for progressive die", Expert Systems with Applications, Vol. 38, pp. 4482-4489, 2011. 